\title{
Analysis on the Influence of PBL Teaching Method on Knowledge Awareness Rate in Teaching of Elderly Lung Cancer Nursing
}

\author{
Qing Ji* \\ Zibo Vocational Institute, Zibo 255314, Shandong Province, China \\ *Corresponding author: Qing Ji, jqzbvc@163.com
}

\begin{abstract}
Objective: To study the effect of Project-Based Learning (PBL) teaching method in lung cancer nursing teaching and its influence on knowledge awareness rates. Methods: The research subjects were 50 nursing interns who entered the same hospital for internship in 2020. The numerical ranking method was used for blind-selection and grouping, where 25 nursing interns were divided into the control group and the internship group each. Among them, the nursing interns in the control group adopted routine nursing teaching management, and the nursing interns in the training group used PBL teaching method for teaching management. The teaching satisfaction rate, teaching quality and knowledge awareness rate of the two groups were compared. Results: Nursing interns in the practice group were better than the control group in their nursing knowledge awareness rate and teaching satisfaction rate after adopting the PBL teaching method, and $\mathrm{p}<0.05$. Conclusion: Through the implementation of PBL teaching method in the clinical nursing teaching of elderly lung cancer in conjunction with cancer nursing related problems, on-site answering is carried out in the way of nursing internship, so that the knowledge of nursing students in the practicing stage will be more in-depth, and the effects and quality of the nursing internship have been steadily improved, which has certain value of promotion in teaching.
\end{abstract}

Keywords: Elderly lung cancer nursing; PBL teaching method; Nursing teaching; Knowledge awareness rate; Teaching effect

Publication date: September 2021; Online publication: September 30, 2021

\section{Introduction}

PBL is a problem-oriented teaching method used in the elderly lung cancer clinical nursing internship, by taking the cases as a guide; taking the clinical lung cancer nursing-related problems as the basis; making the nursing interns as the main subjects of the heuristic internship education. This is so that the practical skills of nursing students in the internship stage are cultivated and the initiative and enthusiasm during the internship are improved ${ }^{[1]}$. Chen Yue et al. ${ }^{[2]}$ studied the application of PBL teaching method in cancer pain nursing teaching show that this teaching method can improve the autonomous learning ability of nursing students during the internship and play a positive role in ensuring the steady improvement of teaching quality. In addition, He Jiaobo et al. ${ }^{[3]}$ have also researched on the application of PBL teaching method in cancer nursing internship nurses, and the results were similar to the former research, where the knowledge awareness rate and the teaching effect during the internship have been greatly improved. In view of this, this research mainly focuses on the application of PBL teaching method in nursing internship on elderly lung cancer. The research results are reported as follows. 


\section{Information and methods}

\subsection{Basic information}

The research subjects are 50 nursing students who entered the same hospital for internship in 2020. The numerical ranking method was used to conduct blind-selection and grouping, and 25 nursing students were divided into the control group and the internship group each. Among them, the male to female ratio of interns in the control group was 5:20, aged 18 to 23 years old, with 10 undergraduates and 15 junior college graduates. The male-to-male ratio of nursing students in the internship group is 6:19, aged 18-22, with 8 undergraduates and 17 college graduates. There is no significant difference in the basic data of the two groups of intern nursing students, so comparative study can be conducted.

\subsection{Internship methods}

Intern nursing students in the control group adopted conventional nursing internship management, where teaching guidance was carried out in conjunction with teaching materials and clinical lung cancer nursing knowledge points, and rigorous teaching plans were formulated. After the internship had been completed and assessed, the teaching satisfaction questionnaires were filled up.

Nursing students in the internship group were introduced to PBL teaching methods on the basis of conventional nursing management teaching. The main teaching content includes:

(1) To enter the clinical practice, it is necessary to clearly understand the clinical teaching tasks on lung cancer, guide the trainees to master the basic teaching knowledge points of PBL, and select practical and enlightening classic lung cancer nursing cases in internship teaching for nursing trainees to conduct nursing evaluation and nursing summary for patients with lung cancer.

(2) Set up a nursing team with 3-5 people, with the group as basis, sort out and summarize the nursing problems of lung cancer discovered during the teaching process, and find out solutions and make detailed records. Meanwhile, the teacher will score and check the group's ability to answer questions and the compilation of report materials, and correct or supplement the existing inadequacies in time.

(3) In the practice of nursing internship, the intern teacher should regularly lead the interns to conduct ward rounds, check the patient's physical signs, and consult the actual feelings of the patients to strengthen the interns' knowledge of lung cancer care as well as the medication management of patients etc. based on actual cases. In the process of teaching, we should also pay attention to the control of the learning atmosphere of nursing students, provide more guidance and more supervision, so that they can develop good habits of independent learning and active thinking ${ }^{[4]}$.

\subsection{Learning indicators evaluation}

\subsubsection{Evaluation of the mastery of theoretical knowledge.}

Through the study of nursing students in the clinical nursing process of lung cancer, they will be evaluated on theoretical knowledge, practical skills and awareness of lung cancer-related knowledge upon the end of the term. Among them, the full score for theoretical knowledge and practical operation skills test is 100 points, and passing grade is 80 points. The requirement for awareness rate of lung cancer-related knowledge is $80 \%$.

\subsubsection{Evaluation of teaching satisfaction rate.}

A self-made questionnaire was distributed to all participating nursing students. The survey was conducted anonymously to summarize and count the satisfaction of the nursing students with the internship teaching process. 


\subsection{Data processing}

All survey data during the internship period were analyzed by the SPSS22.0 software, and the research data significance was confirmed with $\mathrm{p}<0.05$. The count data is expressed in the number of cases (n) and percentage (\%), and the chi-square value test is performed; the measurement data is expressed in $\overline{\mathrm{x}} \pm \mathrm{s}$, and the t-test is applied.

\section{Results}

\subsection{Statistics on the teaching quality and knowledge awareness rate of the two groups of interns}

Upon comparison, it was found that the nursing students in the internship group which adopted PBL teaching have more obvious advantages than the control group in terms of teaching quality improvement and knowledge awareness rate, and the differences are significant. See Table 1.

Table 1. Statistics on the teaching quality and knowledge awareness rate of the two groups of interns

\begin{tabular}{cccc}
\hline Group & $\begin{array}{c}\text { Theoretical Knowledge } \\
(\mathbf{p t s})\end{array}$ & $\begin{array}{c}\text { Practical Skills } \\
(\mathbf{p t s})\end{array}$ & $\begin{array}{c}\text { Knowledge Awareness Rate } \\
(\boldsymbol{\%})\end{array}$ \\
\hline Control $(\mathrm{n}=25)$ & $77.88 \pm 2.55$ & $78.51 \pm 5.23$ & $20(80.00)$ \\
Internship $(\mathrm{n}=25)$ & $88.06 \pm 4.45$ & $88.08 \pm 6.96$ & $24(96.00)$ \\
$\mathrm{P}$ & $<0.05$ & $<0.05$ & $<0.05$ \\
\hline
\end{tabular}

\subsection{Investigation and statistics on teaching satisfaction of the two groups of interns}

It can be seen from Table 2. that the survey result of the teaching satisfaction of the nursing interns in the internship group which adopted PBL teaching method was 23 , and the satisfaction rate was $92.00 \%$, which is significantly higher than that of the control group which received conventional nursing education, and it is statistically significant.

Table 2. Comparison on teaching satisfaction of the two groups of interns

\begin{tabular}{ccccc}
\hline Group & Satisfied & Quite Satisfied & Dissatisfied & Satisfaction Rate $(\boldsymbol{\%})$ \\
\hline Control $(\mathrm{n}=25)$ & $13(52.00)$ & $6(24.00)$ & $6(24.00)$ & $19(76.00)$ \\
Internship $(\mathrm{n}=25)$ & $16(64.00)$ & $7(28.00)$ & $2(8.00)$ & $23(92.00)$ \\
$\mathrm{P}$ & & & $<0.048$ & \\
\hline
\end{tabular}

\section{Discussion}

According to the latest global cancer data released by IARC in 2020, lung cancer accounts for $11.4 \%$ of global new cancer cases and $18.00 \%$ of all cancer deaths. Among them, men are more likely to develop lung cancer. Smoking, air pollution, electrical radiation, gene mutations, and other chronic infections are the main factors for the high incidence of lung cancer. In view of this, during the treatment of lung cancer patients, taking appropriate nursing measures is the best choice to reduce the pain of treatment and improve the efficiency of rehabilitation. PBL teaching method is a new type of teaching method in the lung cancer nursing internship process, which can promote the thinking ability of the nursing interns in the learning process, the ability to solve practical problems, and the ability to summarize and organize the knowledge learned ${ }^{[5]}$.

The results of this study show that the nursing interns in the internship group which carried out PBL were better than the control group in terms of improvement in the quality of nursing teaching and knowledge 
awareness rate during the teaching process (theoretical knowledge score $88.06 \pm 4.45$ vs. $77.88 \pm 2.55$; practical skills score $88.08 \pm 6.96$ vs. $78.51 \pm 5.23$; knowledge awareness rate $96.00 \%$ vs. $80.00 \%$ ), and the satisfaction rate on nursing teaching is also significantly higher than that of the control group $(92.00 \%$ vs. $76.00 \%$ ), and it has statistical research significance. During the internship stage, students have a better grasp and understanding of lung cancer treatment and nursing knowledge, which has good value for promotion in education.

\section{Disclosure statement}

The author declares no conflict of interest.

\section{References}

[1] Huang JN, Zhang SP, Zhao KK et al., 2020, The Application of PBL in Clinical Oncology Teaching. China Continuing Medical Education, 12(21):18-20.

[2] Chen Y, Ju J, 2018, Application of PBL Teaching Method in the Teaching of Cancer Pain Nursing. Journal of Clinical Medical Literature, 2018, 5(47):4+14.

[3] He JB, Yin ZQ, Zhu YQ, 2017, Using PBL in the Teaching of Cancer Pain Treatment for Nursing Undergraduates. China Higher Medical Education, (03):122-123.

[4] Zhang YY, 2020, The Application of PBL Teaching Method in the Teaching of Clinical Nursing Interns. Chinese Medicine Modern Distance Education of China, 12(18):34-35.

[5] Tan Q, 2020, Research on the Value of PBL Teaching Method in Clinical Pediatric Nursing Teaching. China Health Industry, 17(04):120-121+124. 